\title{
Congenital focal abnormalities of the retina and retinal pigment epithelium
}

\author{
Yingna Liu ${ }^{1} \cdot$ Anthony T. Moore ${ }^{1,2}$
}

Received: 3 March 2020 / Revised: 12 March 2020 / Accepted: 17 March 2020 / Published online: 4 May 2020

(c) The Author(s), under exclusive licence to The Royal College of Ophthalmologists 2020

\begin{abstract}
This paper reviews the published literature on a group of developmental disorders of the retina and retinal pigment epithelium which result in focal abnormalities in one or both eyes. They are often asymptomatic, found on routine examination and are generally non-progressive. Some are associated with other systemic abnormalities.
\end{abstract}

\section{Introduction}

Disordered development of the retina and retinal pigment epithelium may result in diffuse retinal abnormalities or focal lesions in one or both eyes. This review will concern itself with focal lesions; these are often asymptomatic as they generally spare the fovea and are commonly identified on routine fundus examination. Most occur as isolated ocular abnormalities but some may be associated with other systemic disorders. Lesions in the former group are only very rarely familial. It is important to recognise which lesions have no systemic associations to prevent unnecessary investigations. These disorders were last reviewed in this journal in 1989 when Donald Gass published his Doyne Lecture [1]; he had carefully characterised many of these

This manuscript is based on Optic UK Lecture given at Royal College of Ophthalmologist Meeting 2019.

Search terms: CHRPE, grouped pigmentation of RPE, grouped albinotic spots, CHRPE and familial adenomatous polyposis, CHRPE and Gardner syndrome, torpedo maculopathy, congenital simple hamartoma of the RPE, combined hamartoma of retina and RPE, retinal astrocytic hamartoma, Aicardi syndrome, microcephaly and chorioretinopathy, KIF11 were the search terms used. These were used to search in the PubMed database.

Anthony T. Moore

Tony.Moore@ucsf.edu

1 Department of Ophthalmology, University of California San Francisco, San Francisco, CA, USA

2 University College London Institute of Ophthalmology, London, UK conditions. Since then, advances in retinal imaging have provided further insights and this paper aims to review current knowledge of this interesting group of disorders.

\section{Solitary congenital hypertrophy of the retinal pigment epithelium (CHRPE)}

The term 'congenital hypertrophy of retinal pigment epithelium' or CHRPE was first coined by Buettner in 1975 to describe a solitary flat, pigmented, round lesion with sharply demarcated margins at the level of retinal pigment epithelium (RPE) (Fig. 1a, b) [2, 3]. There is often a ring of hypopigmentation just within the margins of the lesion, producing a halo or double ring appearance (Fig. 1a) [1, 2] and there may be hypo- or non-pigmented patches within the lesion, termed lacunae (Fig. 1b). These are of variable sizes, sometimes covering almost the entirety of the lesion $[3,4]$. CHRPEs are generally seen in one eye of otherwise normal patients [1, 3], but rarely may be bilateral [4]. They are more commonly seen in the temporal fundus [3, 4], and more likely to occur in the peripheral retina rather than centrally $[2,3]$. It is thought to be a congenital lesion, and has been observed in newborns [5].

On histopathology, the lesions are composed of a single layer of hypertrophic RPE cells containing large pigment granules lying on a thickened Bruch's membrane; there is variable loss of overlying photoreceptors [2, 5]. The hypopigmented ring surrounding some of the lesions are less hyperpigmented hypertrophied RPE cells, while lacunae represent areas where RPE and retinal photoreceptors are absent and only glial cells remain [2]. Ultraviolet fluorescence microscopy of a CHRPE found incidentally in 
Fig. 1 Congenital hypertrophy of the retinal pigment epithelium (CHRPE). a A solitary flat, pigmented, round CHRPE lesion with a ring of hypopigmentation within the margins. b An example of lacunae, a hypopigmented, punched-out patch within another CHRPE lesion.
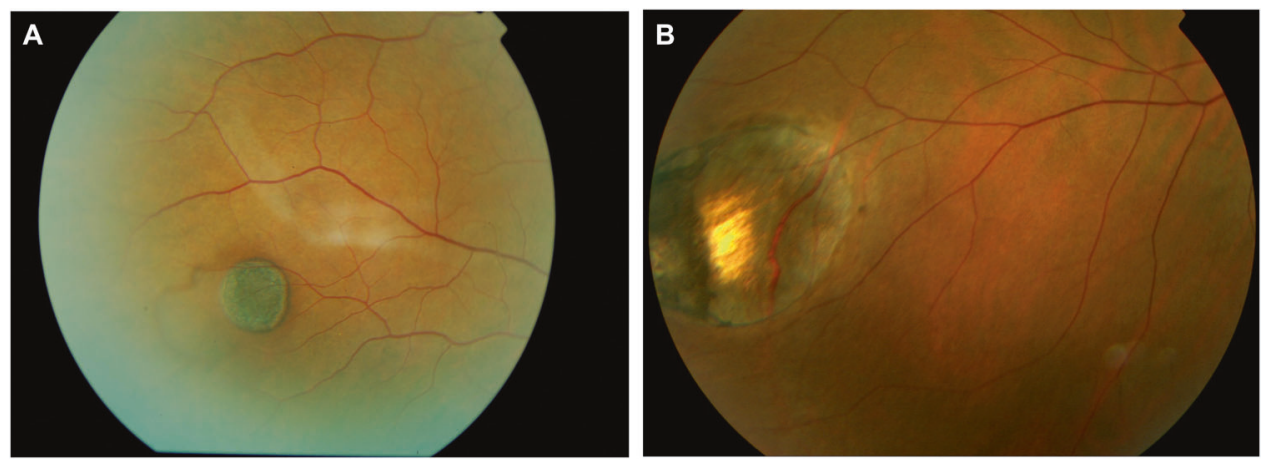

an eye enucleated for melanoma showed a lack of lipofuscin within the CHRPE, suggesting its cells lack capacity to phagocytose photoreceptor outer segments, likely causing photoreceptor degeneration with consequent localised loss of retinal sensitivity [6].

CHRPE is not uncommon, with prevalence reported to be about $1.2 \%$ from a study from one optometry practice [3]. Solitary CHRPE is typically diagnosed incidentally on routine ophthalmologic examination and patients are typically asymptomatic upon diagnosis. CHRPE may rarely cause vision loss when it is complicated by choroidal neovascularization [7].

Even though patients are unaware of scotomas, visual field defects can be demonstrated upon visual field testing, evolving from relative scotomas in young patients to absolute scotomas in older patients $[1,2]$. Overlying retinal vascular abnormalities including vessel sheathing, capillary nonperfusion, and microaneurysmal capillary dilations have also been observed [8], and may also contribute to visual field loss over time.

On imaging, CHRPE lesions are hypoautofluorescent relative to surrounding normal RPE on fundus autofluorescence imaging [9]. Fluorescein angiography shows hypofluorescence in pigmented portion of the lesion, and hyperfluorescence in hypo- or non-pigmented areas [1]. In addition, retinal vascular abnormalities overlying CHRPE may be evident on fluorescein angiography [8]. Optical coherence tomography (OCT) through CHRPE lesions demonstrate thickened hyperreflective RPE with overlying absent or thinning of outer retinal layers and photoreceptor loss [10]. Lesions are universally flat, and RPE is absent in lesions that were considered entirely lacunae, associated with increased optical transmission, while in non-lacunae parts of the lesion, the RPE is thickened.

Solitary CHRPE is generally considered a stable, nonprogressive lesion. However, the majority of CHRPE lesions have been shown to undergo flat slow enlargement over time [11]. The lacunae in CHRPE evolve and enlarge slowly as well, accounting for much of the change in lesion size [4].
Solitary CHRPE are thought to have no malignant potential. However, rarely, an elevated lesion may develop from a CHRPE and this may be associated with prominent feeder vessels and intraretinal exudation causing vision loss due to cystoid macular oedema [12-14]. In one case, pathology demonstrated features consistent with adenocarcinoma [13], while in the other cases, no pathology was available and they were presumed to be RPE adenomas based on morphology and OCT findings [12, 14].

Solitary CHRPE is not associated with ocular or systemic conditions. Specifically, patients with solitary CHRPE are not at greater risk of developing colon cancer [15]. However, CHRPE lesions present in patients with syndromic findings have been reported [5, 16], but no definitive associations found.

Solitary CHRPE is managed by periodic observation. Flat enlargement is possible but very slow and should not affect vision. However, if the lesion starts to grow in thickness, forming a nodule, or develop feeder vessels with exudation, a referral to ocular oncology specialist is warranted.

\section{Congenital grouped pigmentation of the retinal pigment epithelium ('bear tracks')}

Congenital grouped pigmentation of the retinal pigment epithelium (CGP-RPE) is a condition characterised by multiple, small, flat, well-demarcated pigmented lesions of the RPE (Fig. 2a, b). This condition was first recognised by Mauthner in 1868 [17], and the term 'grouped pigmentation of the retina' was first used by Niels Hoëg in 1911 [18].

The size of the pigmented spots varies from point like specks to up to several disc diameters in size, often larger in the periphery and smaller centrally (Fig. 2a, b) [19], resembling animal footprints, hence also known as 'bear tracks'. The group may be composed of 2-30 individual spots, usually $4-10$. The colour of the pigmented spots also varies-the smallest central spots are usually black, and the largest more peripheral spots grey (Fig. 2a) [19]. The 


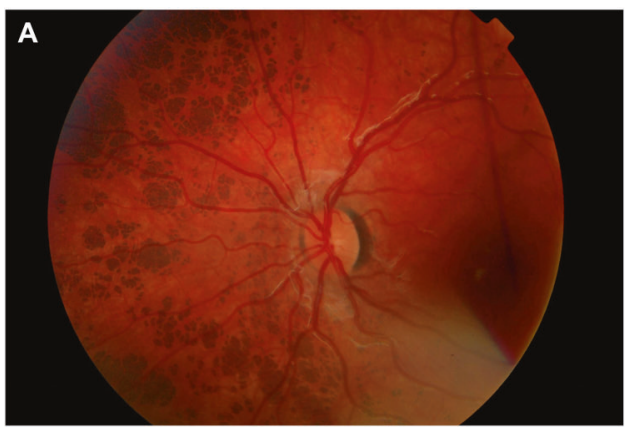

Fig. 2 Congenital grouped pigmentation of the retinal pigment epithelium (CGP-RPE). a The lesions are smaller centrally and enlarge in size toward the periphery, resembling animal footprints. b

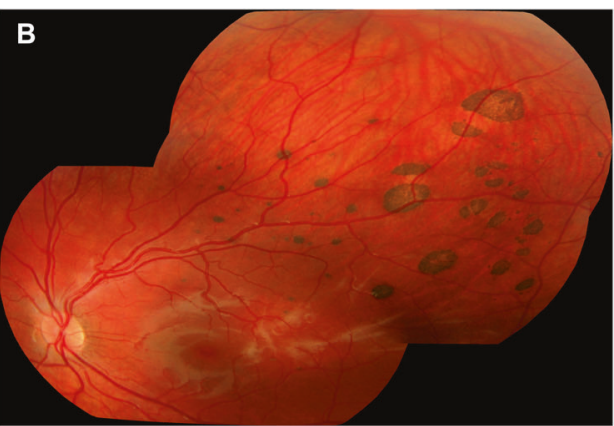

The lesions tend to occur in one sector of the retina, with apex of the sector toward the optic nerve, and tend to be black in the centre and become lighter in colour towards the periphery. borders of the spots are always sharply defined. The lesions tend to only occupy one quadrant of the retina, with the apex of the sector toward the optic disc, spreading out toward the periphery (Fig. 2b) [1, 19]. The macula is rarely involved [1].

Similar to solitary CHRPE lesions, histologically, each pigmented lesion represents increased concentration of pigment granules in otherwise normal RPE cells [20]. However, unlike CHRPE, most pigment granules retained the normal ellipsoidal shape, without significant hypertrophy and hyperplasia of the RPE cells [21]. This histological dissimilarity establishes CGP-RPE as a distinct entity from CHRPE. In addition, the overlying photoreceptors are normal on histology [20].

CGP-RPE is uncommon; the prevalence has been estimated to be around $0.12 \%$ in a general ophthalmic population [22], but the exact prevalence is unknown. It is considered to be congenital, largely non-hereditary, and stationary [1, 19]. However, familial cases have been described [22]. While the majority occur in one eye, it may be present in both eyes of the same patient [23]. Diagnosis is largely made incidentally since these lesions are not associated with any visual symptoms. Indeed, on psychophysical testing, patients are found to have normal visual acuity, visual fields, colour vision and dark adaptation. The electroretinogram and electrooculogram are also normal [23]. Furthermore, no consistent ocular or systemic associations have been established.

Many hypotheses have been proposed to explain the hallmark sectorial distribution of CGP-RPE lesions. Meyer et al. digitally mapped the pattern location of CGP-RPE lesions from published fundus photos, and found that the lesion pattern is similar to cutaneous sectorial pigmentations [24]. They postulated that the sectorial distribution may reflect the pattern of RPE cell migration during embryogenesis, analogous to cutaneous lines of Blaschko and that
CGP-RPE may be caused by a somatic mutation in an early RPE progenitor cell [24].

While a diagnosis of CGP-RPE can be made solely based on characteristic funduscopic findings, imaging studies can be helpful in atypical cases to rule out other diagnoses. On fundus autofluorescence, CGP-RPE lesions usually show uniform hypo-autofluorescence, likely from pigment granules blocking fluorescent signal from lipofuscin [25]. However, occasionally, the lesions can appear hyperautofluorescent in some areas, mixed with hypoautofluorescence in other parts [25]. On fluorescein angiography, the lesions appear hypofluorescent without associated leakage [26]. On OCT, CGP-RPE lesions have been found to show no appreciable change in some cases, or RPE thickening and associated elevation of the overlying ellipsoid zone in others [25].

CGP-RPE requires no treatment or further workup. In particular, CGP-RPE is not associated with familial adenomatous polyposis (FAP) or an increased risk of intestinal cancer [15]; hence, no colonoscopy or genetic workup are indicated. The condition should be observed and the prognosis is excellent.

\section{Grouped congenital albinotic spots of the retinal pigment epithelium ('polar bear tracks')}

A variant of CGP-RPE is congenital albinotic spots of the RPE (CASRPE), also known as 'polar bear tracks'. This condition is characterised by well-circumscribed, chalky white lesions of the same size, shape and distribution as CGP-RPE (Fig. 3a, c) [1]. The lesions occur in one or both eyes, and just like in CGP-RPE, albinotic lesions are more numerous and larger in size in the peripheral retina. Sometimes, melanotic or partially melanotic spots may 
Fig. 3 Grouped congenital albinotic spots of the retinal pigment epithelium. a Widespread patchy chalky white lesions of the left eye in one patient. b Fundus

autofluorescence in the same eye shows that albinotic spots appear hypoautofluorescent. c Diffuse albinotic spots of the left eye in a different patient. d In the same patient, albinotic spots

demonstrates

hyperautofluorescence on fundus autofluorescence.
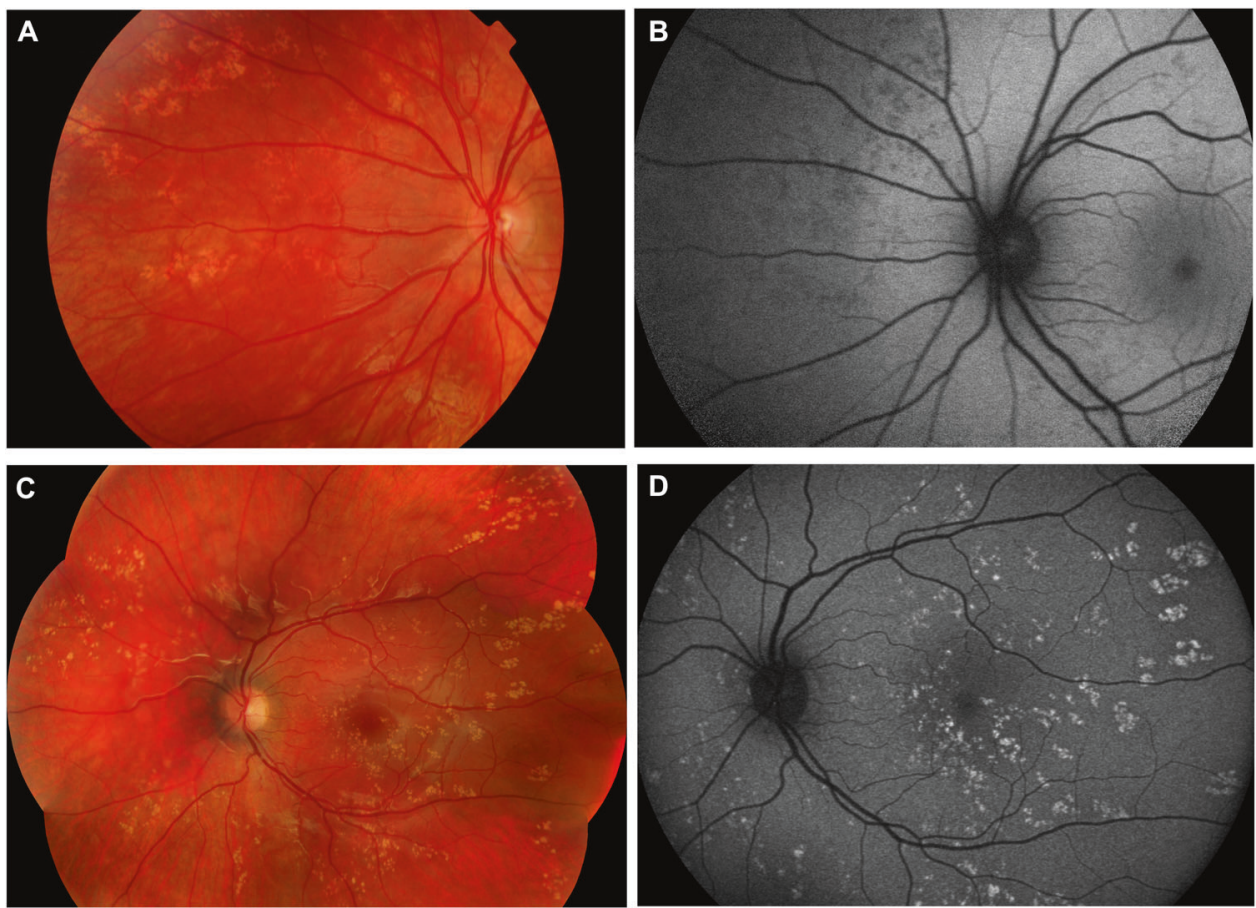

accompany albinotic ones with concurrent appearance of 'bear tracks' and 'polar bear tracks' $[1,26]$.

Even though no histology of grouped congenital albinotic spots has been described, the lesions are thought to represent RPE cells filled with white material, possibly representing an abnormal precursor of melanin, rather than enlarged melanin granules as in CGP-RPE [1]. This is a rare condition, and only a few case reports have been published [23, 27-29].

Just like CGP-RPE, albinotic spots are currently considered congenital, largely non-hereditary, and nonprogressive [27]. However, there was one report of 4 family members with the condition, suggesting that a familial form exists [30]. Interestingly, CGP-RPE and albinotic spots have been reported to occur in the same family, suggesting not only a familial pattern, but also close association with the pathogenesis of CGP-RPE. In one Japanese family, one sister was found to have CGP-RPE in both eyes, while the other sister had albinotic spots bilaterally [23]. In another family of Japanese descent, the mother had albinotic spots in both eyes, while the daughter had both CGP-RPE and albinotic spots [31].

Patients are typically asymptomatic, and have normal visual acuity, visual field, colour vision, and no changes on electroretinography and electrooculography [1, 23, 28]. There are two cases of albinotic spots associated with vision loss: one with choroidal neovascularization [1], and one with an atrophic macular lesion [29]; these are likely to be incidental associations. Rare systemic associations have been described but these are likely to be chance associations or retinal phenocopies.

Fundus autofluorescence imaging of albinotic spots has been reported to show reduced autofluorescence (Fig. 3b) [27]. Some patients with typical albinotic spots may show widespread patchy hyperautofluorescence corresponding to the lesions; this in our experience is a more common pattern (Fig. 3d). Fluorescein angiography demonstrates early and stable hyperfluorescence of the spots without leakage $[1,27]$. Indocyanine green angiography (ICGA) of the lesions demonstrated variable fluorescent behaviour amongst the different spots-some remained hypofluorescent throughout the whole study, some appeared hyperfluorescent throughout all stages [28], while others demonstrated early hypofluorescence, followed by progressive hyperfluorescence in intermediate and late phases [29]. The authors hypothesised that the difference in behaviour on ICGA represented different stages of the disease [29]. However, to date, the natural history of albinotic spots remains unclear.

OCT of hypoautofluorescent lesions showed disrupted ellipsoid zone and increased signal backscattering from the choroid [27], suggesting possible early photoreceptor damage and loss of normal RPE barrier. This is in contrast to the histological finding of CGP-RPE which showed normal photoreceptor layer overlying areas of increased pigment granules in otherwise normal RPE cells [20]. However, no histology study of albinotic spots has been reported. 
Fig. 4 RPE lesions associated with familial adenomatous polyposis (FAP). a, b RPE lesions with irregular border and variable pigmentation in two different patients with FAP.
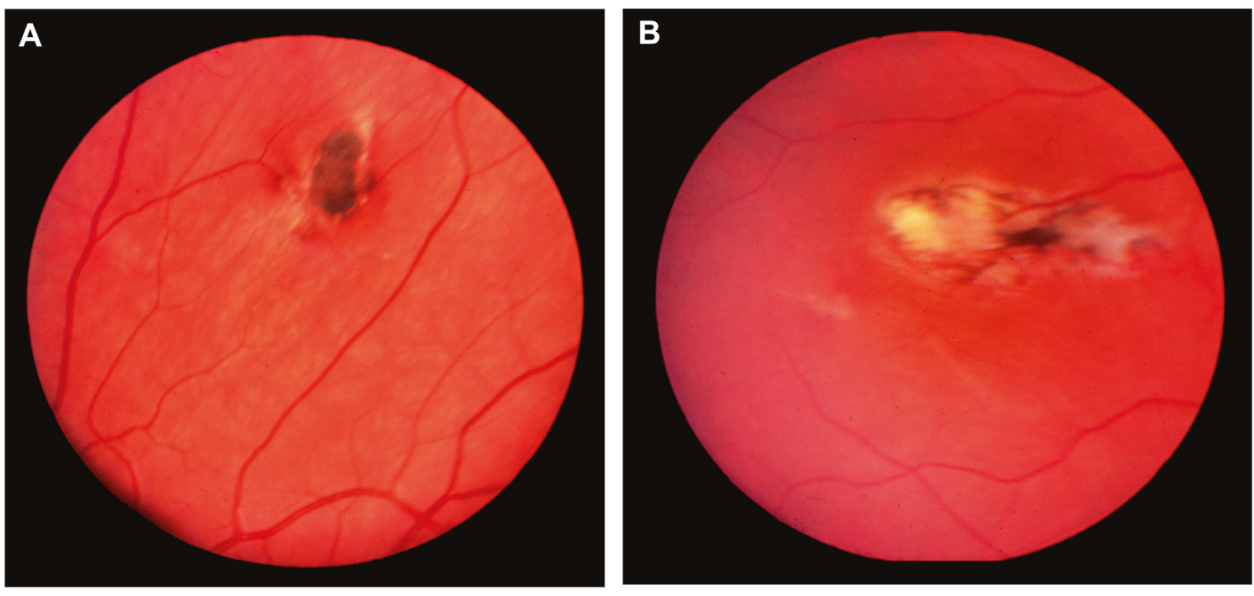

\section{RPE lesions associated with familial adenomatous polypopsis}

FAP is an autosomal dominant condition characterised by numerous adenomatous colonic polyps in youth that inevitably progress to become adenocarcinoma of the colon [32]. This is caused by mutations in the tumour suppressor adenomatous polyposis coli (APC) gene. Gardner syndrome is a variant of FAP disease with extracolonic manifestations, such as osteoma, desmoid tumour, subcutaneous fibromas and others [33]. Ophthalmic manifestations include epidermoid inclusion cysts of the eyelids [33], orbital osteoma, and multiple pigmented fundus lesions that resemble CHRPE (Fig. 4a, b).

Blair and Trempe first reported their observation that multiple pigmented fundus lesions similar to CHRPE were associated with FAP and Gardner syndrome in 1980 [34]. Since then, many investigations have corroborated the observation; these pigmented fundus lesions are very prevalent in FAP, present in more than $75 \%$ of patients, with expressivity dependent on the individual's $A P C$ mutation [35].

The RPE lesions are congenital; they have been observed in newborns and even premature infants [36]. They do not cause symptoms unless the macula is involved. Enlargement of lesions over time has been described in rare cases, but most are stable. Visual field scotomas corresponding to the location of lesions have been reported [37]. Electroretinogram and electrooculogram studies were reported to be normal [37]. Fluorescein angiography shows hypofluorescence in hyperpigmented locations due to blockage, and hyperfluorescence in hypopigmented areas due to window defect [37]. Some studies have shown normal retinal vasculature overlying the lesions, while others have observed retinal vascular changes overlying and surrounding the lesions, including capillary non-perfusion, capillary microaneurysms, attenuation of vessels and others [38]. In addition, it was reported that a significant number, about
$10 \%$, of the lesions were not seen on ophthalmoscopy and could only be detected by angiography [38].

Because of the lesions' similarity to CHRPE clinically, they have frequently been referred to as CHRPE associated with FAP. However, there is clear histopathology evidence demonstrating cellular hypertrophy, hyperplasia and even rarely retinal invasion and formation of a minute mushroom-shaped tumour, consistent with hamartomatous malformation rather than simple hypertrophy [39, 40]. Furthermore, multiple authors have confirmed the generalised defect in melanogenesis, with evidence of abnormal presence of macromelanosomes in RPE cells, pigment inclusions in the basement membrane of the RPE [39, 40].

The term pigmented ocular fundus lesions of FAP has been used to clearly distinguish from solitary CHRPE lesions and grouped congenital CHRPE, neither of which are associated with adenomatous polyps or colorectal cancers [15]. Unlike solitary CHRPE, fundus lesions associated with FAP are multiple and bilateral, and tend to have irregular borders (Fig. 4a, b) [15]. The number of lesions per eye is variable but appears to be consistent within a family of affected patients [41]. Unlike congenital grouped CHRPE, FAP associated fundus lesions are more likely to be bilateral, and have a random distribution in the fundus, rather than occupy a sector of the fundus as commonly observed in grouped pigmentation (Fig. 2b) [15].

The mutated gene responsible for FAP is the tumour suppressor gene APC located on chromosome 5q21-q22, which was identified in 1991 [42, 43]; since then, hundreds of different mutations have been identified. Mutations in FAP are likely responsible for dysfunctional ocular melanogenesis observed on histology. The expression of fundus lesions is at least partially determined by the length of truncated protein product [35], as well as the location of mutation. Mutations in the exons $1-8$ of the $A P C$ gene are not associated with fundus pigmented lesions, while those in exons 10-15, or between codons 463 and 1387, are associated with fundus pigmented lesions [44]. However, 
Fig. 5 Torpedo maculopathy. a A typical lesion is present in the temporal macula of the left eye straddling the horizontal raphe, with a tail pointing towards the fovea. b Fundus

autofluorescence of the same lesion demonstrates a mostly hypoautofluorescent lesion with a rim of hyperautofluorescence along the inferior margin. c Optical coherence tomography through the lesion demonstrates a subretinal cleft with elevation of the neurosensory retina.
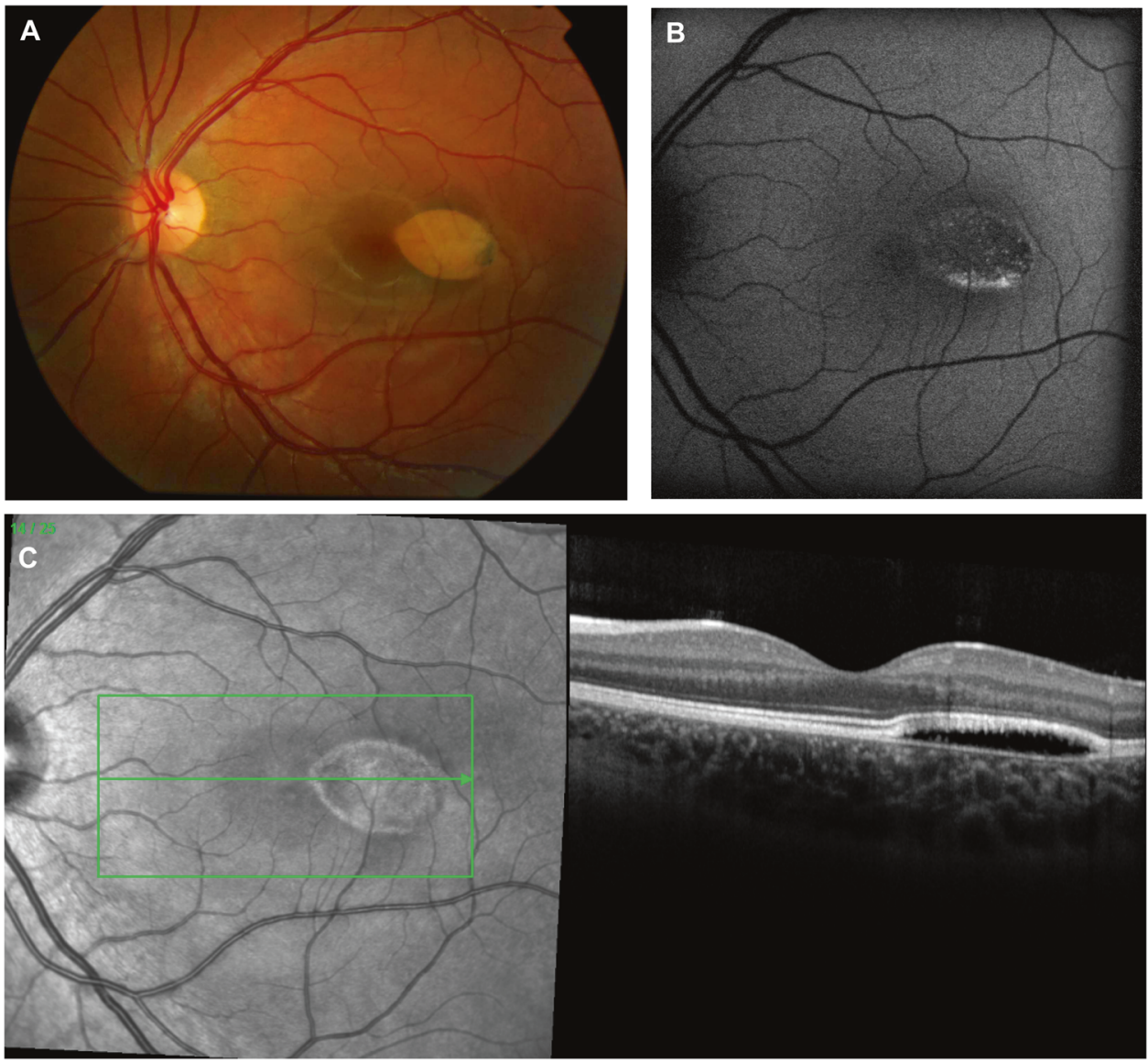

the mutation location was not able to predict the fundus phenotype $100 \%$ of the time, indicating that it is not the only factor responsible for the presence and number of retinal lesions in FAP [45].

For families with positive fundus findings, the presence of characteristic lesions can be predictive and serve as an early clinical marker for the development of polyps. Traboulsi et al. in a large series of 16 families with Gardner's syndrome showed that the presence of four or more pigmented lesions between the two eyes was a both sensitive (70-80\%) and specific (>90\%) clinical marker for Gardner's syndrome [46]. However, about $20-30 \%$ of FAP and Gardner families do not have fundus lesions [41, 47]. Therefore, while a positive retinal examination can be predictive for FAP, a negative examination cannot rule out the disease, unless other affected family members are known to have multiple RPE lesions. A negative fundus examination is therefore of little value in the setting of suspected de novo FAP. As a result, retinal examination is now rarely used as a predictive indicator in families with FAP, being replaced by more specific molecular genetic testing.

Of note, multiple bilateral fundus RPE lesions are not associated with other types of gastrointestinal polyposis, such as familial polyposis coli, hereditary nonpolyposis colorectal cancer, and Peutz-Jeghers syndrome. It is specific to FAP.

\section{Torpedo maculopathy}

In 1989, Roseman and Gass described a 'solitary, sharply circumscribed ... placoid' lesion with a wedge-shaped 'tail' in the macula' of an asymptomatic 12-year-old boy with 20/ 20 vision. They called the lesion a 'hypopigmented naevus of the RPE' [48]. In 1993, the term 'torpedo maculopathy' was first introduced by Dr. Mark Daily to describe this congenital lesion that localises to the temporal fovea with a tip or tail pointing towards the central macula, resembling a torpedo (Fig. 5a) [49]. Since then, many case reports have been published describing this unique and immediately recognisable condition.

The lesions may be bilateral, and can be hypopigmented or contain melanotic components. They measure about 2-3 $\mathrm{mm}$ horizontally and $1 \mathrm{~mm}$ vertically, universally located in the macula, straddling the horizontal raphe (Fig. 5a) [50]. Lesions are oval with a characteristic point aimed toward the foveola, but the temporal aspect may have a 'frayed tail' 
Fig. 6 Congenital simple hamartoma of the RPE. a A focal, well-circumscribed, jetblack lesion just temporal to the fovea in the left eye. b Fundus autofluorescence of the same lesion demonstrates hypoautofluorescence from heavy pigmentation in the lesion. c Optical coherence tomography shows prominent hyperreflectivity in the area of the lesion with abrupt and complete posterior optical shadowing.
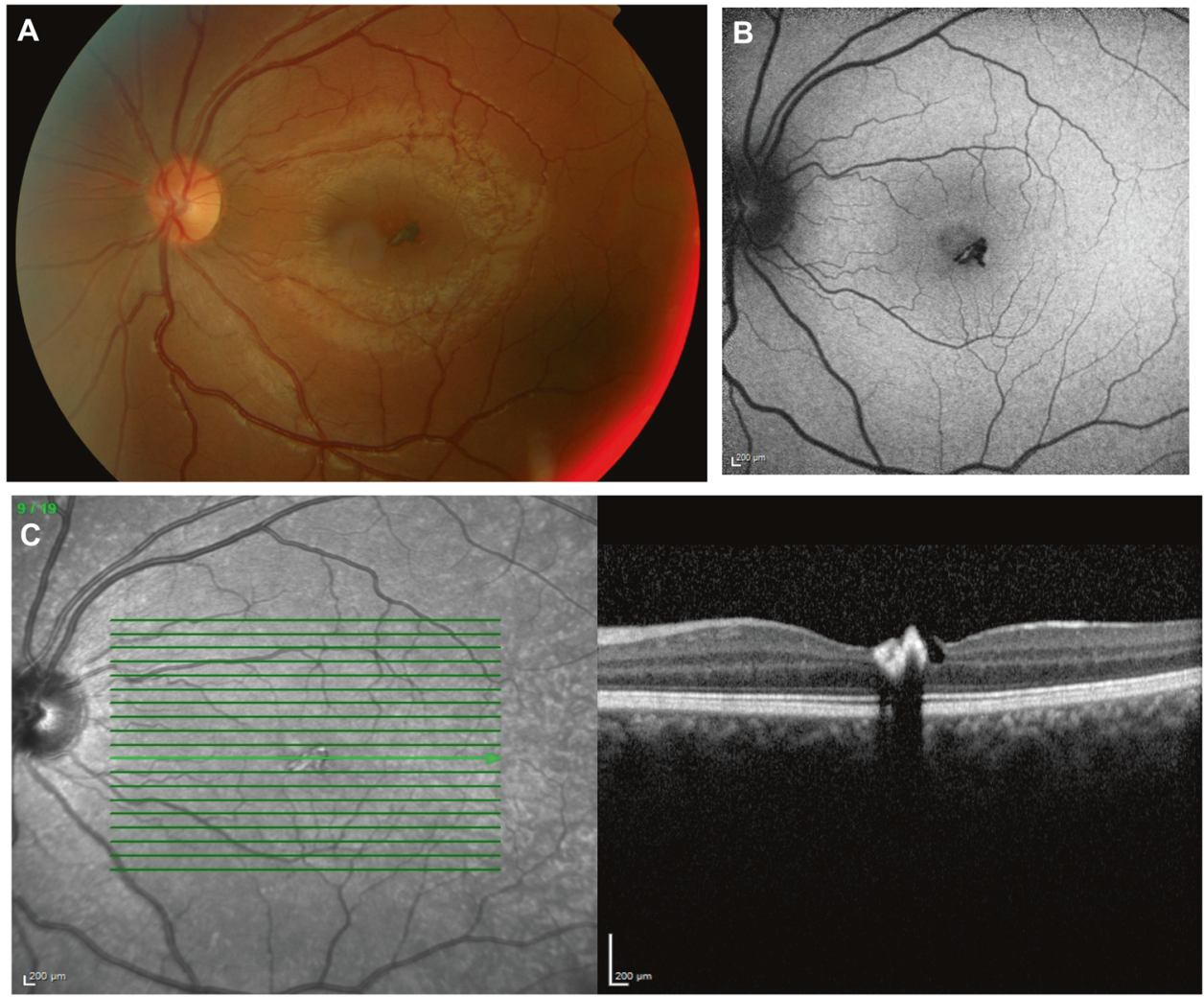

or a rounded margin. Torpedo maculopathy should be distinguished from congenital pigmented lesions associated with Gardner's syndrome, which also characteristically have an oval shape with 'fish-tail' at one or both ends. But unlike torpedo lesions, Gardner's syndrome-associated RPE lesions manifest a random distribution in the fundus, are multiple per eye, usually bilateral, smaller and more irregular in shape, and are associated with a positive family history of intestinal polyps and cancer.

Torpedo maculopathy is a congenital condition, nonhereditary, and believed to be non-progressive. However, most case reports to date have a short follow-up period. Recently, a study reviewed the findings of published cases of torpedo lesions and found that older patients tend to have more retinal attenuation and excavation and were more likely to have visual field defects and loss of retinal sensitivity compared with younger patients, suggesting that this condition may be progressive [51]. Unfortunately, there is a lack of longitudinal follow up studies to confirm this hypothesis.

Patients are typically asymptomatic, with normal visual acuity, colour vision, and normal electroretinogram and electrooculogram [52, 53]. Rarely, when the lesion is associated with retinal excavation that encroaches the fovea, visual acuity can be affected [54]. One case report described vision loss due to choroidal neovascularization associated with a torpedo lesion that responded well to bevacizumab injections [55]. Visual field and microperimetry testing show variable results. Some patients have no visual field defects, while others, in particular those with more prominent retinal structural changes in the lesion, had scotoma corresponding to the site of the lesion [54]. No clear ocular or systemic associations have been established. No familial cases of torpedo maculopathy have been reported.

The aetiology of torpedo maculopathy is currently only speculative. The consistent location and size of this condition implies a congenital defect that occurred at a specific time-point during foetal ocular development [50]. There are a number of competing hypotheses about the mechanism of the developmental defect $[50,56]$ but this is currently unknown.

No histology studies of this lesion have been described to date, and detailed characterisation so far largely depends on multimodal imaging. Fundus autofluorescence almost always shows decreased or absent autofluorescence, which occasionally could be surrounded by a rim of increased autofluorescence (Fig. 5b). Fluorescein angiography studies show transmission hyperfluorescence without leakage [52]. This likely represents atrophy of the RPE at the lesion site.

OCT findings of torpedo maculopathy can be variable and demonstrates a spectrum of abnormalities. The RPE appears attenuated and thin with increased signal transmission to the choroid causing hyperreflectivity of the choroid [53, 57]. The overlying retina can be normal in 
Fig. 7 Combined hamartoma of the retina and RPE. $a, b$ Two eyes of the same infant with a family history of neurofibromatosis 2 (NF2) showing evidence of bilateral combined hamartomas, indicating that the infant also has NF2. c An ill-defined, lightly pigmented, elevated mass located in the macula associated with epiretinal membrane and vascular tortuosity. $\mathbf{d}$ Late phase fluorescein angiogram of the same lesion demonstrates diffuse late punctate leakage within the lesion. e Optical coherence tomography through the lesion shows a diffusely thickened retina with intraretinal fluid and disorganisation of the inner and outer retinal architecture.
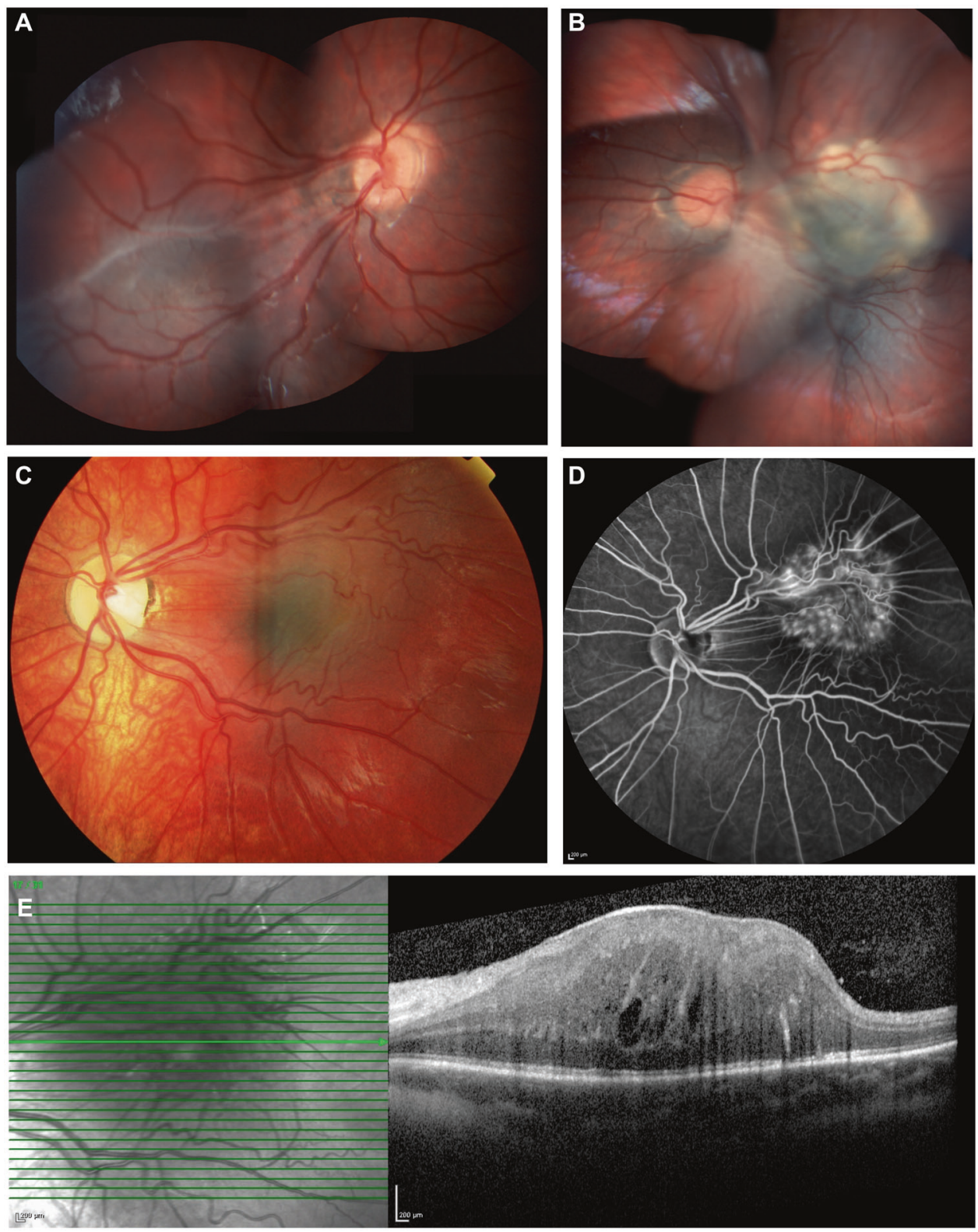

young patients, but in older patients is frequently thin and attenuated, with disruption of outer retinal layers, particularly in areas with RPE loss [57]. Many are accompanied by a variably sized subretinal cleft with elevation of the neurosensory retina (Fig. 5c). In some cases, the lesions are found to be deeply excavated with degeneration of retinal layers within the lesion, and when present, they are associated with overlying loss of retinal sensitivity [51].

More recently, OCT angiography has been employed to further characterise the torpedo lesions. In areas of retinal cleft, there is reported hyporeflectivity and a loss of deep retinal capillary network and choroidal vessels, with decreased flow in the cleft but increased flow in choroidal vessels surrounding the cleft [57].

\section{Congenital simple hamartoma of the RPE}

First recognised by Laqua in 1981, congenital simple hamartoma of the RPE is a rare benign pigmented lesion [58]. Gass described its unique characteristics in 1989 as a 'focal, nodular, jet black' lesion that involves the full thickness of the retina and 'spills onto the inner retinal surface in an umbrella fashion' (Fig. 6a) [1]. It is well circumscribed, $<1 \mathrm{~mm}$ in diameter and $1-2.5 \mathrm{~mm}$ in thickness, frequently located in the macular area, and may be associated with subtle feeding arterioles and draining venules [59] and/or vitreomacular adhesion at the margin in many cases [60].

Congenital simple hamartoma of the RPE is usually asymptomatic and in most cases is detected incidentally 
later in life. It is assumed to be congenital, although no cases have been reported in infants. It is also thought to be stationary. Even though mild radial retinal traction is commonly noted in congenital simple hamartoma of the RPE, most patients have normal visual acuity unless the fovea is involved in the lesion itself or the lesion is associated with foveal traction. Secondary ERM formation and severe vitreomacular traction causing vision impairment has been reported [61]. In this case the hamartoma was removed surgically via a pars plana approach and histopathology showed a nodular proliferation of hyperplastic RPE cells, and these RPE cells also demonstrated fibrous metaplasia [61]. The exact histopathology of congenital simple hamartoma of the RPE has not yet been established.

Other rare complications include retinal haemorrhages [60], macular exudates and macular oedema which in one case improved with intravitreal anti-VEGF treatment [62]. Full thickness macular holes have also been reported [63].

RPE hamartomas have a characteristic appearance on retinal imaging. Fundus autofluorescence demonstrates a blockage of autofluorescence at the site of heavy pigmentation resulting in hypoautofluorescence of the lesion (Fig. 6b). Fluorescein angiography may show a feeding artery entering the lesion and a draining vein exiting, with hypofluorescence throughout the angiography and occasionally may show hyperfluorescence without leakage in late frames [64].

OCT shows elevated retina with prominent surface hyperreflectivity with abrupt and complete optical shadowing posteriorly (Fig. 6c) [59]. The surrounding RPE and retina has normal anatomy. More recently, reports with OCT angiography showed variable vasculature findings: one report identified the presence of intrinsic vasculature at the level of inner and outer capillary plexus, with vessels occupying the full thickness of the lesion [65], and another report noted a radial microvascular arrangement [64].

Given its benign natural history, most lesions require only periodic observation. Rarely, in cases with foveal involvement or foveal traction leading to vision decline, surgical or medical interventions can be considered when appropriate.

\section{Combined hamartoma of the retina and retinal pigment epithelium}

Combined hamartoma of retina and retinal pigment epithelium was first described by Gass in 1973 in a series of seven patients [66], and in 1984, Schachat further described this entity in 60 cases reported by members of the Macula Society [67]. It is typically an ill-defined, grey-white, elevated mass located in the posterior pole involving the retina, RPE and overlying vitreous to varying degrees, frequently associated with vascular tortuosity and vitreoretinal interface changes (Fig. 7a-c) [66-68]. Prior to a better understanding of this benign lesion in the 1970 s to 1980 s, eyes were sometimes enucleated for suspected malignancy.

Combined hamartoma of retina and RPE is rare. It typically presents in childhood, most commonly with decreased visual acuity and/or strabismus [68]. The lesion is presumed to be congenital; the youngest patient reported was a two-week old infant [68]. It is mostly unilateral, but can be bilateral particularly when associated with neurofibromatosis type 2 (Fig. 7a, b). In the majority of patients, it is sporadic, but familial cases have been reported and most commonly associated with neurofibromatosis. Combined hamartoma of the retina and RPE is a well-characterised association of neurofibromatosis, but other reports of associations with brachio-otic syndrome, orbital fibrosis, Gorlin syndrome and a few others may represent incidental findings rather than true syndromic associations.

Progressive vision loss due to tractional distortion of the fovea from retinal gliosis and vitreoretinal interface changes is common [67, 68]. Patients can experience decreased visual acuity and metamorphopsia from foveal traction and macular dragging or from vitreous haemorrhage associated with retinal neovascularization [69]. Choroidal neovascularization is another uncommon cause of vision loss.

Fluorescein angiography shows early hypofluorescence from blockage of choroidal vessels by RPE proliferation, abnormal vasculature with increased calibre, arteriovenous communication, and diffuse late staining or leakage (Fig. 7d) [67]. On OCT, the lesion shows a disruption of inner neurosensory retina and variable degree of involvement of outer retina (Fig. 7e) [70]. There is prominent vitreoretinal traction on enhanced depth imaging OCT, with 'mini-peaks' that arise from disorganisation of inner retinal layers, resembling a sawtooth shape, as well as 'maxi-peaks' that arise from retinal folds involving the entire thickness of the retina [71]. OCT angiography is able to better characterise the vascular abnormalities within combined hamartoma [70], and may be helpful in the early diagnosis of associated choroidal neovascularization.

On histopathology, combined hamartoma manifests as an elevated mass containing disorganised retinal tissue with vascular changes and secondary membrane formation from glial elements and proliferating RPE [72]. The lesion is not stationary, and enlargement and evolution of mass over time is well documented. When combined hamartoma is associated with progressive vision loss due to retinal traction, surgery may be considered; spontaneous resolution of traction may occur, but is rare. Pars plana vitrectomy and membrane peel has been reported to improve vision in some cases, despite some recurrences [73]. However, when the lesion involves the full thickness retina, vitrectomy with 
Fig. 8 Retinal astrocytic hamartoma. a, b are fundus photos of a patient with TSC with bilateral lesions. c A solitary elevated mass with internal calcification in the fundus of the right eye in a patient without a diagnosis of

TSC. d Fundus autofluorescence of the same lesion demonstrates hyperautofluorescence in areas of internal calcification. e Optical coherence tomography scanning through the lesion demonstrates an abrupt transition from normal retina to an elevated mass with disorganisation of the inner retina and internal moth-eaten empty spaces that correlate with intratumoral calcification, in addition to complete posterior shadowing.
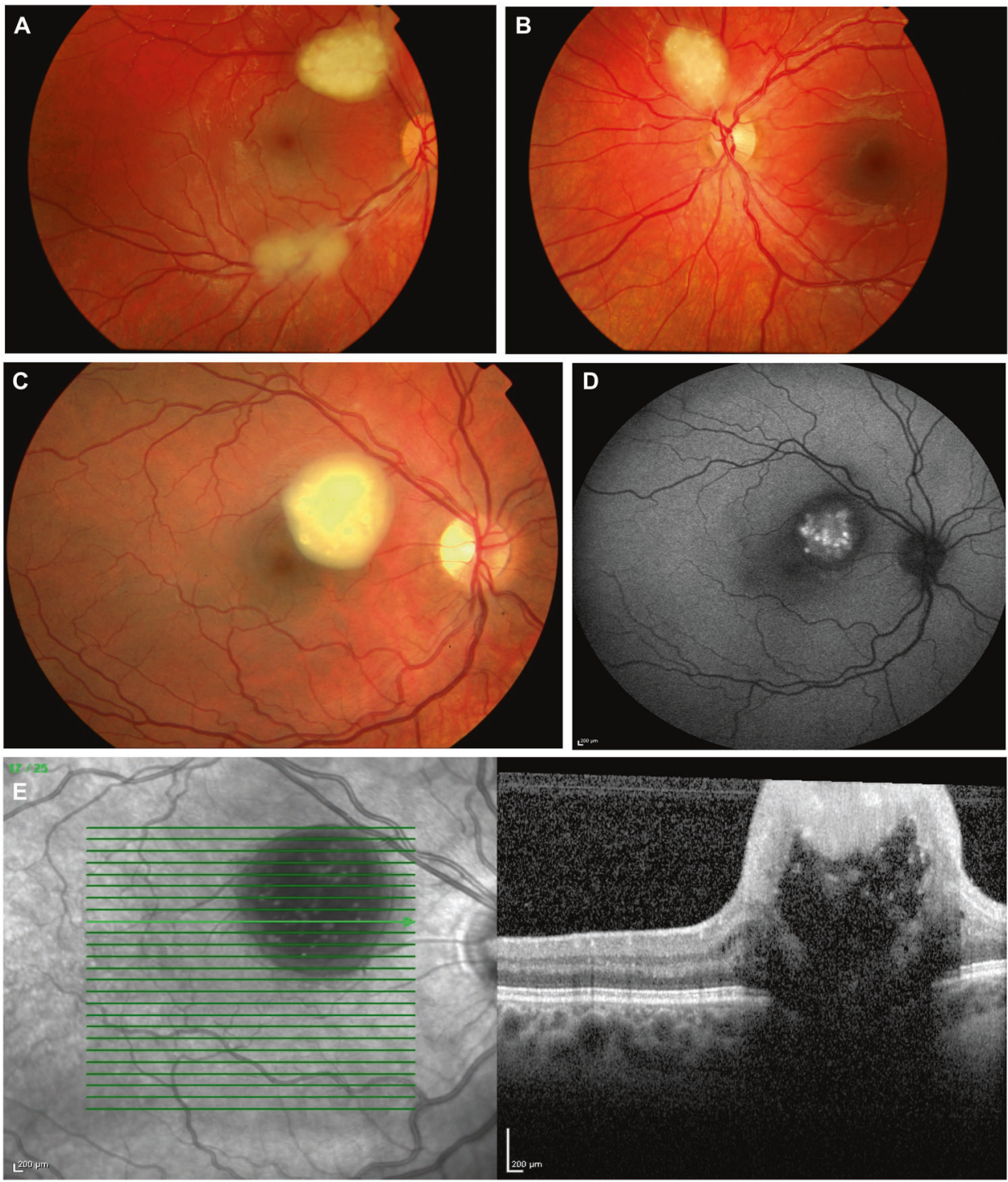

membrane peel is generally unhelpful. Recently a new classification system based on location, fundus findings regarding traction or retinal detachment, and OCT findings, has been proposed that would assist in determining follow up in interval and decision making for possible surgical intervention [74].

\section{Retinal astrocytic hamartoma}

Retinal astrocytic hamartoma (RAH) is a rare, benign glial tumour, best known for its association with tuberous sclerosis complex (TSC), but it may also occur as an isolated disorder [75]. Among patients with TSC, about one third to half of patients have RAH [75, 76]. TSC or Bournville disease is a multisystem autosomal dominant disorder caused by TSC1/TSC2 gene mutations that lead to dis-inhibition of the mammalian target of rapamycin (mTOR), a key regulator of cell proliferation and tumour growth [77]. This then results in the many phenotypic features of TSC.

RAH has a wide range of clinical appearances, ranging from a faint, flat, translucent or semi-translucent, noncalcified intraretinal lesion (inferior lesion in Fig. 8a) to a large yellow-grey, calcified, multinodular mulberry-like tumour (Fig. 8a-c). All tumours localise in the nerve fibre layer but can also involve other retinal layers [78]. There is a predilection for the posterior pole in the fundus (Fig. 8a-c). In cases associated with TSC, it manifests as bilateral, multifocal lesions (Fig. 8a, b). Patients with retinal findings are more likely to have TSC2 mutation, and have concomitant systemic manifestations including subependymal glial cell astrocytomas, renal angiomyolipomas, cognitive impairment and epilepsy [76]. 
Most recently, RAH lesions in patients with TSC have been classified into four groups based on both clinical appearance and OCT findings [79]: Type 1 RAH is a round shaped, relatively flat, semitransparent, glistening retinal mass within the retinal nerve fibre layer, without disturbance of the underlying retina or RPE; it has a gradual transition from normal retina to tumour. Type $2 \mathrm{RAH}$ is a slightly elevated lesion with mild traction on the tumour surface, with some degree of retinal disorganisation, as well as abrupt transition from normal retina to tumour (Fig. 8a). Type $3 \mathrm{RAH}$ is a calcified mushroom lesion with internal 'moth-eaten' optically empty spaces representing intratumoral calcification (Fig. 8a-c); it has a gradual transition between the tumour and surrounding normal retina. Type 4 RAH is an elevated, dome-shaped, optically empty tumour, with a large single cavity within the mass and optical shadowing posterior to the tumour. Interestingly, each type of lesion has different systemic TSC correlations. Patients with type 2 lesions are more likely to have a greater number of cutaneous fibrous plaques; those with type 3 lesions are more likely to have subependymal giant-cell astrocytomas; while those with type 4 lesions have a higher incidence of pulmonary lymphangiomyomatosis [79].

On histopathology, RAH shows variability as well. The small astrocytic hamartoma (type 1) is confined to the nerve fibre layer of the retina. The more aggressive tumours (types 3 and 4) appear very similar on pathology to subependymal giant cell astrocytoma of TSC; tumours show extensive necrosis and calcification [80]. On immunohistochemistry, cells show a mixed glioneuronal phenotype, showing positive immunoreactivity to neuron-specific enolase and glial fibrillary acidic protein [80].

RAH can be diagnosed clinically based on appearance on examination and retinal imaging. Fundus autofluorescence can be variable depending on the type of RAH lesion present. It can demonstrate hyperautofluorescence from internal calcification (Fig. 8d). OCT findings depend on the types of lesion, but characteristically shows a gradual or abrupt transition (Fig. 8e) from normal retina to a hyperreflective mass with thickening in retinal nerve fibre layer, with varying degrees of retinal disorganisation, or motheaten spaces that correlate with intratumoral calcification (Fig. 8e), and posterior shadowing [78, 79].

Retinal hamartomas are generally asymptomatic, and isolated cases that are extramacular are often diagnosed later in life. Usually retinal hamartomas show little or no growth [81], but rarely can grow aggressively causing severe ocular complications [80]. Vision loss from RAH can be due to vitreous haemorrhage, retinal neovascularization, retinal detachment, subretinal haemorrhage, neovascular glaucoma, macular oedema or even rarely a mass effect blocking the visual axis. A number of different treatment modalities have been tried.
Intravitreal anti-VEGF agents have been used to treat macular oedema and neovascularization and photodynamic therapy has been shown to induce regression of vascularised, aggressive RAH [82]. More recently, systemic mTOR inhibitors, including both sirolimus and everolimus, have been found to control or decrease the thickness of RAH lesions with excellent patient adherence and mild adverse effects in small series of patients [83, 84]. In one particular case, exudative retinal detachment associated with RAH that had failed intravitreal anti-VEGF and laser treatment, responded well to oral everolimus treatment with resolution of retinal detachment at the end of 4 months [84].

\section{Other syndromic disorders with characteristic congenital focal lesions of retina and RPE}

\section{Aicardi syndrome}

Aicardi syndrome was first described by Aicardi et al. in 1965 [85]. It is a systemic syndrome characterised by a triad of agenesis or dysgenesis of the corpus callosum, infantile spasm, and chorioretinal lacunae [85, 86]. Vertebral and rib malformations are common [87]. There are often complex developmental abnormalities of the brain including microcephaly, cortical polymicrogyria and periventricular heterotopia $[88,89]$. Infantile spasms are usually the earliest clinical manifestation of Aicardi syndrome, generally apparent between 3 and 6 months of age. The vast majority of cases are female, but it has been reported in XXY male infants.

Ophthalmologic findings are also variable and include microphthalmos (Fig. 9a, b), persistent pupillary membrane (Fig. 9c), developmental abnormalities of the optic nerve (Fig. 9d), characteristic chorioretinal lacunae (Fig. 9d, e), retinal detachment (Fig. 9f), anomalous retinal vessels [90, 91].

Chorioretinal lacunae can be unilateral or bilateral. They present as round, flat, well-circumscribed, 'punched out' lesions of the retina, mostly in the posterior pole, hypopigmented, usually yellow or white in colour (Fig. 9d). They vary in size from half to three times the disc diameter, and are not known to change in size over time. OCT imaging shows an outer retinal cavity filled with subretinal fluid with absent RPE and thinning or absence of choroid (Fig. 9e). In a single published case, OCT showed intraretinal cysts and detachment of the neurosensory retina overlying the lacunae [92].

On histopathology, lacunae represent excavation of the RPE through the choroid to the bare sclera, consisting of full thickness defects of the RPE and choroid, with intact but abnormal overlying retina [93]. 
Fig. 9 Aicardi syndrome. a Normal-sized right eye of a patient with Aicardi syndrome. b Microphthalmic left eye in the same patient. c Left eye demonstrates persistent pupillary membrane. d Right eye demonstrates optic nerve coloboma and multiple wellcircumscribed, round chorioretinal lesions in the posterior pole, consistent with chorioretinal lacunae. One large lacunae beneath the optic disc appears to have subretinal fluid, confirmed on OCT. e Optical coherence tomography reveals an outer retinal cavity filled with subretinal fluid over one of the lacunae. f Left eye shows a complete funnel retinal detachment.
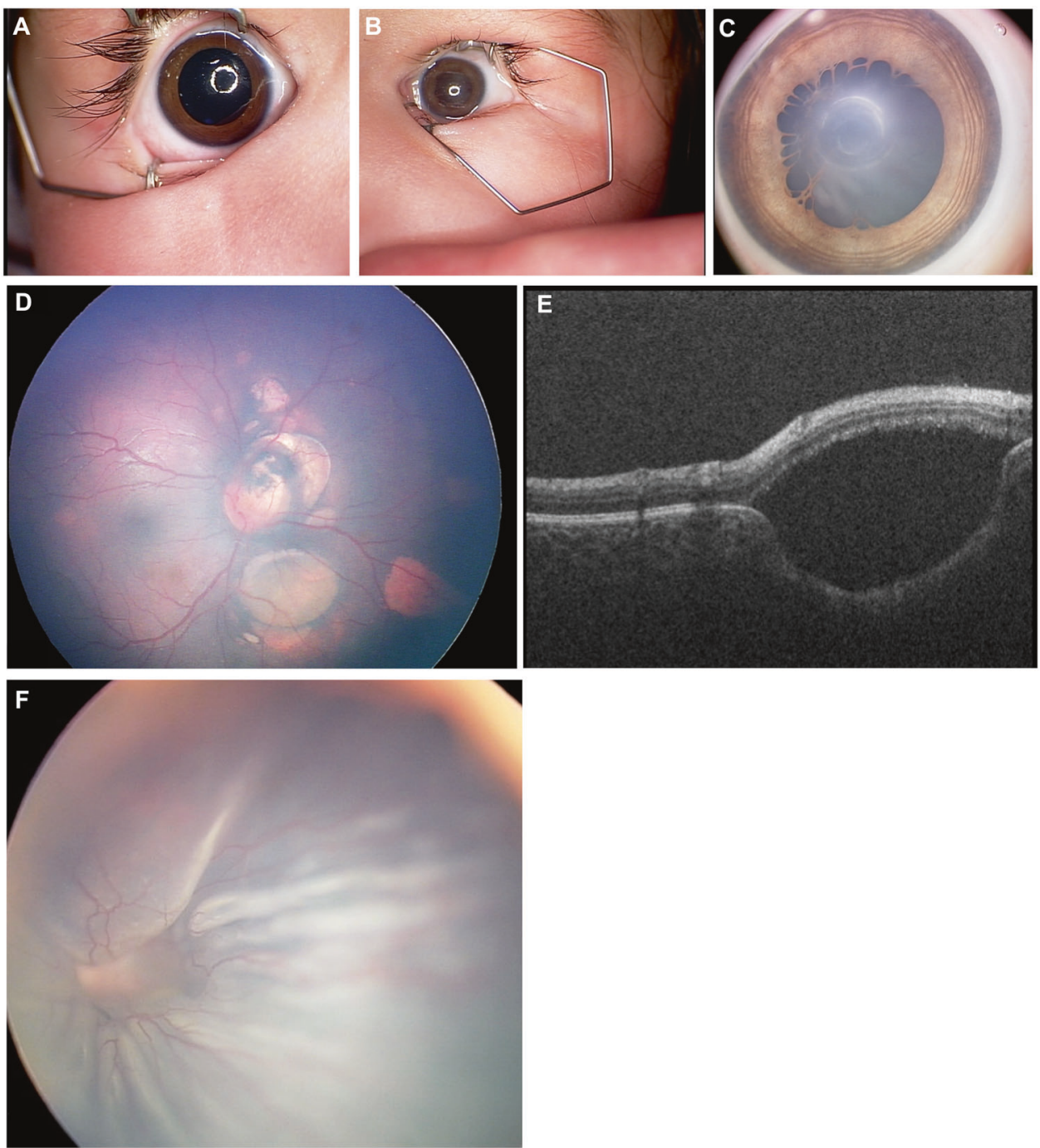

Aicardi syndrome is very rare with a reported incidence of around 1 in 110,000 live births [91, 94]. The aetiology remains unknown. Even though the cases are sporadic, it is thought to have a genetic basis but no causative gene has been identified. It is only seen in females or $47, \mathrm{XXY}$ karyotype males suggesting that this is an X-linked dominant disorder with embryonic lethality in males. The precise genetic cause remains elusive despite the advent of next generation sequencing.

\section{Microcephaly chorioretinopathy syndrome KIF11 disease (MIM 152950)}

First described by Feingold and Bartoshesky in 1992, microcephaly with or without chorioretinopathy, lymphedema or mental retardation (MCLMR) is a rare autosomal dominant condition. It was previously thought to be a distinct clinical entity from chorioretinal dysplasia, microcephaly and mental retardation syndrome (CDMMR) [95]. However, recently, there is evidence of significant clinical and molecular overlap to suggest that CDMMR and MCLMR are allelic disorders, constituting a distinct congenital microcephaly syndrome with wide clinical spectrum [96]. In particular, mutations in KIF11, a gene that encodes a homotetramer kinesin motor EG5, were identified to be the pathogenic for a significant proportion of cases within the spectrum of MCLMR and CDMMR [96, 97]. Incomplete penetrance is relatively common with KIF11 mutations with some family members carrying a KIF11 mutation having normal head circumference and eye examination [97].

The retinal phenotype may be very variable. Typical findings include bilateral chorioretinopathy with focal atrophy, vessel attenuation and pigment clumping usually outside the macula (Fig. 10a-c). The retinal changes are thought to be congenital and stationary or slowly progressive; one patient was followed for 9 years without 
Fig. 10 Microcephaly chorioretinopathy syndrome

KIF11 disease. a Left eye of a patient with KIF11 disease demonstrates chorioretinopathy with atrophy, local vessel attenuation and pigment clumping inferior to the macula. b Fundus autofluorescence of the same eye demonstrates hypoautofluorescence in areas of chorioretinopathy consistent with RPE atrophy. c Optical coherence tomography shows loss of retinal lamination and absence of outer retinal architecture within areas of the lesion.
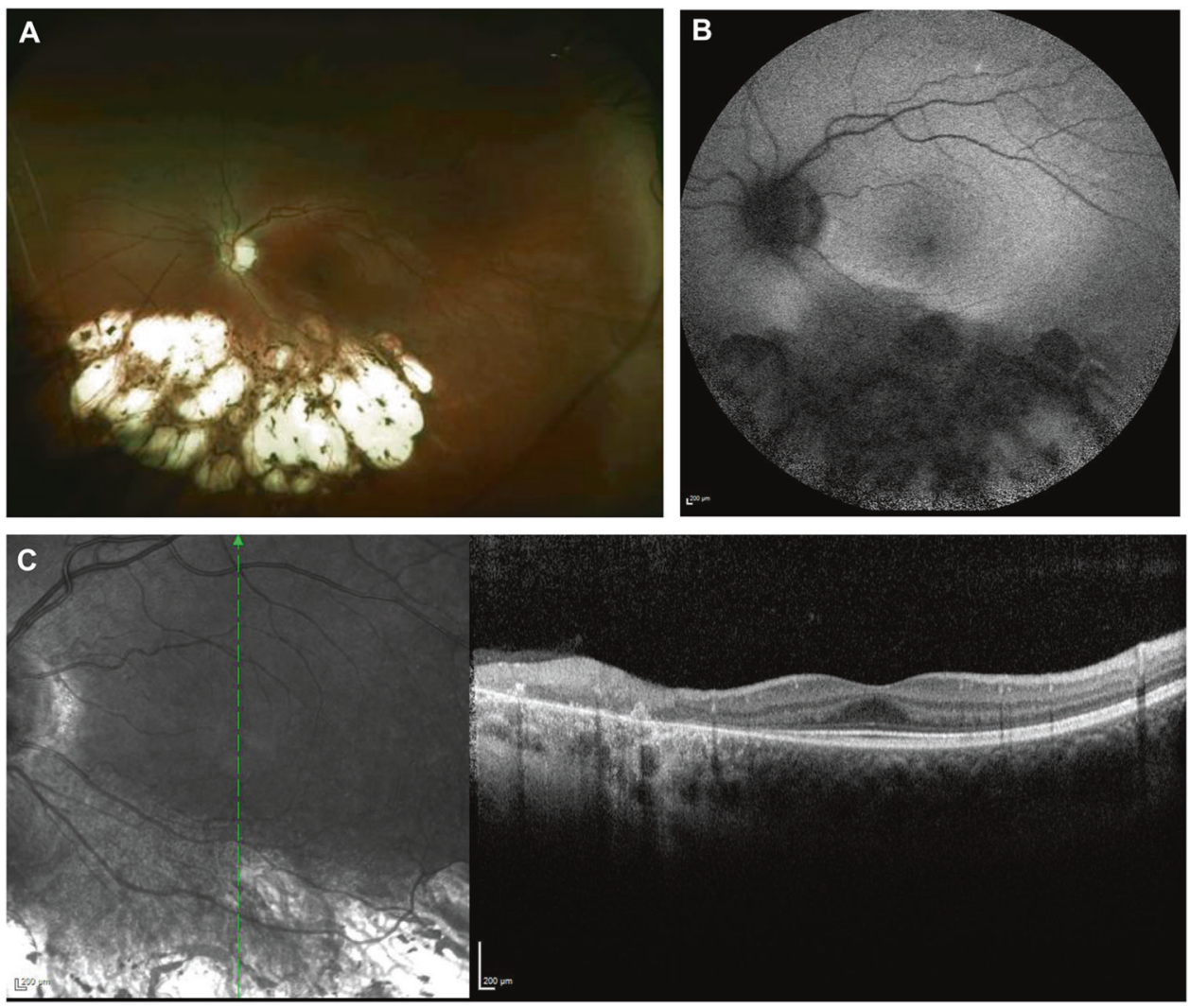

significant progression [98]. Some patients with KIF11 mutations may develop atrophic changes of the macula, as demonstrated on OCT and hypoautofluorescence on FAF [99]. The peripheral retina in most patients shows mild diffuse RPE disturbance with or without focal atrophy. Full field electroretinogram typically demonstrates generalised subnormal and delayed rod and cone function, and pattern electroretinogram demonstrates macular dysfunction.

More recently, heterozygous KIF11 mutations have been reported to be associated with microcephaly and retinovascular abnormalities similar to those seen in familial exudative vitreoretinopathy, further expanding the clinical spectrum associated with KIF11 mutations [99, 100].

Acknowledgements The authors are grateful to the medical photographers at Moorfields Eye Hospital, London, Hospital for Children, London, and University of California San Francisco, for their expertise in imaging young patients.

Funding The authors did not receive any funding support for the work of this manuscript.

\section{Compliance with ethical standards}

Conflict of interest The authors declare that they have no conflict of interest.

Publisher's note Springer Nature remains neutral with regard to jurisdictional claims in published maps and institutional affiliations.

\section{References}

1. Gass JD. Focal congenital anomalies of the retinal pigment epithelium. Eye. 1989;3(Pt 1):1-18.

2. Buettner H. Congenital hypertrophy of the retinal pigment epithelium. Am J Ophthalmol. 1975;79:177-89.

3. Coleman P, Barnard NAS. Congenital hypertrophy of the retinal pigment epithelium: prevalence and ocular features in the optometric population. Ophthalmic Physiol Opt. 2007;27:547-55.

4. Shields CL, Mashayekhi A, Ho T, Cater J, Shields JA. Solitary congenital hypertrophy of the retinal pigment epithelium: clinical features and frequency of enlargement in 330 patients. Ophthalmology. 2003;110:1968-76.

5. Champion R, Daicker BC. Congenital hypertrophy of the pigment epithelium: light microscopic and ultrastructural findings in young children. Retina. 1989;9:44-8.

6. Lloyd WC, Eagle RC, Shields JA, Kwa DM, Arbizo VV. Congenital hypertrophy of the retinal pigment epithelium. Electron Microsc Morphometric Observations Ophthalmol. 1990;97:1052-60.

7. Garoon RB, Harbour JW. Congenital hypertrophy of the retinal pigment epithelium presenting with secondary choroidal neovascularization. Ophthalmic Surg Lasers Imaging Retina. 2018:49:276-7.

8. Cleary PE, Gregor Z, Bird AC. Retinal vascular changes in congenital hypertrophy of the retinal pigment epithelium. Br J Ophthalmol. 1976;60:499-503.

9. Takahashi BS, Bruè C, Spaide RF. Autofluorescence characteristics of congenital hypertrophy of the retinal pigment epithelium. Retin Cases Brief Rep. 2008;2:259-61.

10. Fung AT, Pellegrini M, Shields CL. Congenital hypertrophy of the retinal pigment epithelium: enhanced-depth imaging optical 
coherence tomography in 18 cases. Ophthalmology. 2014;121:251-6.

11. Chamot L, Zografos L, Klainguti G. Fundus changes associated with congenital hypertrophy of the retinal pigment epithelium. Am J Ophthalmol. 1993;115:154-61.

12. Shields JA, Shields CL, Singh AD. Acquired tumors arising from congenital hypertrophy of the retinal pigment epithelium. Arch Ophthalmol. 2000;118:637-41.

13. Shields JA, Shields CL, Eagle RC, Singh AD. Adenocarcinoma arising from congenital hypertrophy of retinal pigment epithelium. Arch Ophthalmol. 2001;119:597-602.

14. Pefkianaki M, Mashayekhi A, Shields JA, Shields CL. Congenital hypertrophy of retinal pigment epithelium with overlying thin adenoma. Retina. 2017;37:e69-70.

15. Shields JA, Shields CL, Shah PG, Pastore DJ, Imperiale SM. Lack of association among typical congenital hypertrophy of the retinal pigment epithelium, adenomatous polyposis, and Gardner syndrome. Ophthalmology 1992;99:1709-13.

16. Kurz GH, Zimmerman LE. Vagaries of the retinal pigment epithelium. Int Ophthalmol Clin. 1962;2:441-64. https://insights. ovid.com/crossref?an $=00004397-196206000-00011$. Accessed 5 Jan 2020.

17. Mauthner L. A textbook of ophthalmoscopy. Viena: Tendler; 1868.

18. Hoeg Niels. Grouped pigmentation of the ocular fundus. Klin Monatsbl Augenheilkd. 1911;49:49-77.

19. Blake EM. Congenital grouped pigmentation of the retina. Trans Am Ophthalmol Soc. 1926;24:223-33.

20. Shields JA, Tso MO. Congenital grouped pigmentation of the retina. Histopathologic description and report of a case. Arch Ophthalmol. 1975;93:1153.

21. Regillo CD, Eagle RC, Shields JA, Shields CL, Arbizo VV. Histopathologic findings in congenital grouped pigmentation of the retina. Ophthalmology. 1993;100:400-5.

22. de Jong PT, Delleman JW. Familial grouped pigmentation of the retinal pigment epithelium. $\mathrm{Br} \mathrm{J}$ Ophthalmol. 1988;72:439-41.

23. Kadoi C, Hayasaka S, Hayasaka Y, Matsumoto M, Nagaki Y. Bilateral congenital grouped pigmentation of the retina in one girl and bilateral congenital albinotic spots of the retina in her sister. Retina. 1999;19:571-2.

24. Meyer CH, Rodrigues EB, Mennel S, Schmidt JC, Kroll P. Grouped congenital hypertrophy of the retinal pigment epithelium follows developmental patterns of pigmentary mosaicism. Ophthalmology. 2005;112:841-7.

25. Wang H, Ly A, Yapp M, Assaad N, Kalloniatis M. Multimodal imaging characteristics of congenital grouped hyper- and hypopigmented fundus lesions. Clin Exp Optom. 2019

26. Turell ME, Leonardy NJ, Singh AD. A unique presentation of grouped congenital hypertrophy of the retinal pigment epithelium. Ophthalmic Genet. 2011;32:162-4.

27. Kim DY, Hwang JC, Moore AT, Bird AC, Tsang SH. Fundus autofluorescence and optical coherence tomography of congenital grouped albinotic spots. Retina. 2010;30:1217-22.

28. Karacorlu SA, Karacorlu M, Ozdemir H, Sanisoglu H. Indocyanine green angiographic findings in congenital grouped albinotic spots. Retina. 2006;26:470-2.

29. Battaglia Parodi M, Iacono P. Indocyanine green angiography pattern of congenital grouped albinotic retinal pigment epithelial spots. Semin Ophthalmol 2004;19:114-6.

30. Arana LA, Sato M, Arana J. Familial congenital grouped albinotic retinal pigment epithelial spots. Arch Ophthalmol. 2010;128:1362-4.

31. Watanabe M, Makino S, Tampo H. An unusual presentation of concurrent congenital grouped pigmentation of the retina with albinotic spots. Case Rep Ophthalmol. 2015;6:39-43.
32. Gardner EJ. A genetic and clinical study of intestinal polyposis, a predisposing factor for carcinoma of the colon and rectum. Am J Hum Genet. 1951;3:167-76.

33. Jones EL, Cornell WP. Gardner's syndrome; review of the literature and report on a family. Arch Surg. 1966;92:287-300.

34. Blair NP, Trempe CL. Hypertrophy of the retinal pigment epithelium associated with Gardner's syndrome. Am J Ophthalmol. 1980;90:661-7.

35. Wallis YL, Macdonald F, Hultén M, Morton JE, McKeown CM, Neoptolemos JP, et al. Genotype-phenotype correlation between position of constitutional APC gene mutation and CHRPE expression in familial adenomatous polyposis. Hum Genet. 1994;94:543-8.

36. Aiello LP, Traboulsi EI. Pigmented fundus lesions in a preterm infant with familial adenomatous polyposis. Arch Ophthalmol. 1993;111:302-3.

37. Santos A, Morales L, Hernandez-Quintela E, Jiménez-Sierra JM, Villalobos JJ, Panduro A. Congenital hypertrophy of the retinal pigment epithelium associated with familial adenomatous polyposis. Retina. 1994;14:6-9.

38. Touriño R, Rodríguez-Ares MT, López-Valladares MJ, GómezUlla F, Gómez-Torreiro M, Capeans C. Fluorescein angiographic features of the congenital hypertrophy of the retinal pigment epithelium in the familial adenomatous polyposis. Int Ophthalmol. 2005;26:59-65.

39. Traboulsi EI, Murphy SF, de la Cruz ZC, Maumenee IH, Green WR. A clinicopathologic study of the eyes in familial adenomatous polyposis with extracolonic manifestations (Gardner's syndrome). Am J Ophthalmol. 1990;110(Nov):550-61.

40. Kasner L, Traboulsi EI, Delacruz Z, Green WR. A histopathologic study of the pigmented fundus lesions in familial adenomatous polyposis. Retina. 1992;12:35-42.

41. Romania A, Zakov ZN, McGannon E, Schroeder T, Heyen F, Jagelman DG. Congenital hypertrophy of the retinal pigment epithelium in familial adenomatous polyposis. Ophthalmology. 1989;96:879-84.

42. Groden J, Thliveris A, Samowitz W, Carlson M, Gelbert L, Albertsen $\mathrm{H}$, et al. Identification and characterization of the familial adenomatous polyposis coli gene. Cell. 1991;66:589-600.

43. Kinzler KW, Nilbert MC, Su LK, Vogelstein B, Bryan TM, Levy $\mathrm{DB}$, et al. Identification of FAP locus genes from chromosome 5q21. Science. 1991;253:661-5.

44. Olschwang S, Tiret A, Laurent-Puig P, Muleris M, Parc R, Thomas G. Restriction of ocular fundus lesions to a specific subgroup of APC mutations in adenomatous polyposis coli patients. Cell. 1993;75:959-68.

45. Valanzano R, Cama A, Volpe R, Curia MC, Mencucci R, Palmirotta $\mathrm{R}$, et al. Congenital hypertrophy of the retinal pigment epithelium in familial adenomatous polyposis. Novel criteria of assessment and correlations with constitutional adenomatous polyposis coli gene mutations. Cancer. 1996;78:2400-10.

46. Traboulsi EI, Krush AJ, Gardner EJ, Booker SV, Offerhaus GJ, Yardley $\mathrm{JH}$, et al. Prevalence and importance of pigmented ocular fundus lesions in Gardner's syndrome. N Engl J Med. 1987;316:661-7.

47. Moore AT, Maher ER, Koch DJ, Charles SJ. Incidence and significance of congenital hypertrophy of the retinal pigment epithelium (CHRPE) in familial adenomatous polyposis coli (FAPC). Ophthalmic Paediatr Genet. 1992;13:67-71.

48. Roseman RL, Gass JD. Solitary hypopigmented nevus of the retinal pigment epithelium in the macula. Arch Ophthalmol. 1992;110:1358-9.

49. Daily MJ. Torpedo maculopathy or paramacular spot syndrome. Chicago, Illinois; 1993 p. 11;7. (New Dimensions in Retina Symposium). 
50. Shields CL, Guzman JM, Shapiro MJ, Fogel LE, Shields JA. Torpedo maculopathy at the site of the fetal "bulge.". Arch Ophthalmol. 2010;128:499-501.

51. Wong EN, Fraser-Bell S, Hunyor AP, Chen FK. Novel optical coherence tomography classification of torpedo maculopathy. Clin Exp Ophthalmol. 2015;43:342-8.

52. Rigotti M, Babighian S, Carcereri De Prati E, Marchini G. Three cases of a rare congenital abnormality of the retinal pigment epithelium: torpedo maculopathy. Ophthalmologica. 2002;216:226-7.

53. Tsang T, Messner LV, Pilon A, Lombardi L. Torpedo maculopathy: in-vivo histology using optical coherence tomography. Optom Vis Sci. 2009;86:E1380-1385.

54. Trevino R, Kiani S, Raveendranathan P. The expanding clinical spectrum of torpedo maculopathy. Optom Vis Sci. 2014;91: S71-78.

55. Jurjevic D, Böni C, Barthelmes D, Fasler K, Becker M, Michels $\mathrm{S}$, et al. Torpedo maculopathy associated with choroidal neovascularization. Klin Monatsbl Augenheilkd. 2017;234:508-14.

56. Teitelbaum BA, Hachey DL, Messner LV. Torpedo maculopathy. J Am Optom Assoc. 1997;68:373-6.

57. Papastefanou VP, Vázquez-Alfageme C, Keane PA, Sagoo MS. Multimodality imaging of torpedo maculopathy with swept-source, en face optical coherence tomography and optical coherence tomography angiography. Retin Cases Brief Rep. 2018;12:153-7.

58. Laqua $\mathrm{H}$. Tumors and tumor-like lesions of the retinal pigment epithelium. Ophthalmologica. 1981;183:34-8.

59. Shields CL, Materin MA, Karatza EC, Shields JA. Optical coherence tomography of congenital simple hamartoma of the retinal pigment epithelium. Retina. 2004;24:327-8.

60. Shields CL, Shields JA, Marr BP, Sperber DE, Gass JDM. Congenital simple hamartoma of the retinal pigment epithelium: a study of five cases. Ophthalmology. 2003;110:1005-11.

61. Barnes AC, Goldman DR, Laver NV, Duker JS. Congenital simple hamartoma of the retinal pigment epithelium: clinical, optical coherence tomography, and histopathological correlation. Eye. 2014;28:765-6.

62. Bach A, Gold AS, Villegas VM, Wildner AC, Latiff A, Ehlies FJ, et al. Simple hamartoma of the retinal pigment epithelium with macular edema. Optom Vis Sci. 2015;92:S48-50.

63. Van de Moere A, Clark JB. Congenital simple hamartoma of the retinal pigment epithelium with a full-thickness macular hole. Retin Cases Brief Rep. 2009;3:80-2.

64. Rodrigues MW, Cavallini DB, Dalloul C, Shields CL, Jorge R. Retinal sensitivity and photoreceptor arrangement changes secondary to congenital simple hamartoma of retinal pigment epithelium. Int J Retin Vitr. 2019;5:5.

65. Arjmand P, Elimimian EB, Say EAT, Shields CL. Optical coherence tomography angiography of congenital simple hamartoma of the retinal pigment epithelium. Retin Cases Brief Rep. 2019;13:357-60.

66. Gass JD. An unusual hamartoma of the pigment epithelium and retina simulating choroidal melanoma and retinoblastoma. Trans Am Ophthalmol Soc. 1973;71:171-83. discussions 184-185

67. Schachat AP, Shields JA, Fine SL, Sanborn GE, Weingeist TA, Valenzuela RE, et al. Combined hamartomas of the retina and retinal pigment epithelium. Ophthalmology. 1984;91:1609-15.

68. Shields CL, Thangappan A, Hartzell K, Valente P, Pirondini C, Shields JA. Combined hamartoma of the retina and retinal pigment epithelium in 77 consecutive patients visual outcome based on macular versus extramacular tumor location. Ophthalmology. 2008; 115:2246. e3

69. Helbig $\mathrm{H}$, Niederberger $\mathrm{H}$. Presumed combined hamartoma of the retina and retinal pigment epithelium with preretinal neovascularization. Am J Ophthalmol. 2003;136:1157-9.

70. Arrigo A, Corbelli E, Aragona E, Manitto MP, Martina E, Bandello F, et al. Optical coherence tomography and optical coherence tomography angiography evaluation of combined hamartoma of the retina and retinal pigment epithelium. Retina. 2019;39:1009-15.

71. Arepalli S, Pellegrini M, Ferenczy SR, Shields CL. Combined hamartoma of the retina and retinal pigment epithelium: findings on enhanced depth imaging optical coherence tomography in eight eyes. Retina. 2014;34:2202-7.

72. Font RL, Moura RA, Shetlar DJ, Martinez JA, McPherson AR. Combined hamartoma of sensory retina and retinal pigment epithelium. Retina. 1989;9:302-11.

73. Cohn AD, Quiram PA, Drenser KA, Trese MT, Capone A. Surgical outcomes of epiretinal membranes associated with combined hamartoma of the retina and retinal pigment epithelium. Retina. 2009;29:825-30.

74. Dedania VS, Ozgonul C, Zacks DN, Besirli CG. Novel classification system for combined hamartoma of the retina and retinal pigment epithelium. Retina. 2018;38:12-9.

75. Rowley SA, O'Callaghan FJ, Osborne JP. Ophthalmic manifestations of tuberous sclerosis: a population based study. Br J Ophthalmol. 2001;85:420-3.

76. Aronow ME, Nakagawa JA, Gupta A, Traboulsi EI, Singh AD. Tuberous sclerosis complex: genotype/phenotype correlation of retinal findings. Ophthalmology. 2012;119:1917-23.

77. Schwartz RA, Fernández G, Kotulska K, Jóźwiak S. Tuberous sclerosis complex: advances in diagnosis, genetics, and management. J Am Acad Dermatol. 2007;57:189-202.

78. Shields CL, Say EAT, Fuller T, Arora S, Samara WA, Shields JA. Retinal astrocytic hamartoma arises in nerve fiber layer and shows "moth-eaten" optically empty spaces on optical coherence tomography. Ophthalmology. 2016;123:1809-16.

79. Pichi F, Massaro D, Serafino M, Carrai P, Giuliari GP, Shields $\mathrm{CL}$, et al. Retinal astrocytic hamartoma: optical coherence tomography classification and correlation with tuberous sclerosis complex. Retina. 2016;36:1199-208.

80. Shields JA, Eagle RC, Shields CL, Marr BP. Aggressive retinal astrocytomas in four patients with tuberous sclerosis complex. Trans Am Ophthalmol Soc. 2004;102:139-47. discussion 147148

81. Zimmer-Galler IE, Robertson DM. Long-term observation of retinal lesions in tuberous sclerosis. Am J Ophthalmol. 1995;119:318-24.

82. House RJ, Mashayekhi A, Shields JA, Shields CL. Total regression of acquired retinal astrocytoma using photodynamic therapy. Retin Cases Brief Rep. 2016;10:41-3.

83. Zhang Z-Q, Shen C, Long Q, Yang Z-K, Dai R-P, Wang J, et al. Sirolimus for retinal astrocytic hamartoma associated with tuberous sclerosis complex. Ophthalmology. 2015;122:1947-9.

84. Nallasamy N, Seider MI, Gururangan S, Mruthyunjaya P. Everolimus to treat aggressive retinal astrocytic hamartoma in tuberous sclerosis complex. J AAPOS. 2017;21:328-31.

85. Aicardi J, Lefebvre J, Lerique-Koechlin A. Spasms in flexion, callosal agenesis, ocular abnormalities: a new syndrome. Electroencephalogr Clin Neurophysiol. 1995;19:609-10.

86. Aicardi J, Chevrie JJ, Rousselie F. Spasma-in-flexion syndrome, callosal agenesis, chorioretinal abnormalities. Arch $\mathrm{Fr}$ Pediatr.1969;26:1103-20.

87. Chevrie JJ. The Aicardi syndrome. Recent Adv Epilepsy. 1986;3:189-210.

88. Menezes AV, MacGregor DL, Buncic JR. Aicardi syndrome: natural history and possible predictors of severity. Pediatr Neurol 1994;11:313-8.

89. Aicardi J. Aicardi syndrome. Brain Dev. 2005;27:164-71.

90. Fruhman G, Eble TN, Gambhir N, Sutton VR, Van den Veyver IB, Lewis RA. Ophthalmologic findings in Aicardi syndrome. J AAPOS. 2012;16:238-41. 
91. Shirley K, O’Keefe M, McKee S, McLoone E. A clinical study of Aicardi syndrome in Northern Ireland: the spectrum of ophthalmic findings. Eye. 2016;30:1011-6.

92. Martel JN, Rutar T, Lujan BJ, de Alba Campomanes A. Chorioretinal architecture in Aicardi syndrome: an optical coherence tomography and fluorescein angiography study. J AAPOS. 2011;15:308-10.

93. McMahon RG, Bell RA, Moore GR, Ludwin SK. Aicardi's syndrome. A clinicopathologic study. Arch Ophthalmol. 1984;102:250-3.

94. Kroner BL, Preiss LR, Ardini M-A, Gaillard WD. New incidence, prevalence, and survival of Aicardi syndrome from 408 cases. J Child Neurol. 2008;23:531-5.

95. Fryns JP, Smeets E, Van den Berghe H. On the nosology of the "primary true microcephaly, chorioretinal dysplasia, lymphoedema" association. Clin Genet. 1995;48:131-3.

96. Ostergaard P, Simpson MA, Mendola A, Vasudevan P, Connell FC, van Impel A, et al. Mutations in KIF11 cause autosomal-dominant microcephaly variably associated with congenital lymphedema and chorioretinopathy. Am J Hum Genet. 2012;90:356-62.
97. Jones GE, Ostergaard P, Moore AT, Connell FC, Williams D, Quarrell O, et al. Microcephaly with or without chorioretinopathy, lymphoedema, or mental retardation (MCLMR): review of phenotype associated with KIF11 mutations. Eur J Hum Genet. 2014;22:881-7.

98. Balikova I, Robson AG, Holder GE, Ostergaard P, Mansour S, Moore AT. Ocular manifestations of microcephaly with or without chorioretinopathy, lymphedema or intellectual disability (MCLID) syndrome associated with mutations in KIF11. Acta Ophthalmol. 2016;94:92-8.

99. Birtel J, Gliem M, Mangold E, Tebbe L, Spier I, Müller PL, et al. Novel insights into the phenotypical spectrum of KIF11-associated retinopathy, including a new form of retinal ciliopathy. Investig Ophthalmol Vis Sci. 2017;58: 3950-9.

100. Robitaille JM, Gillett RM, LeBlanc MA, Gaston D, Nightingale M, Mackley MP, et al. Phenotypic overlap between familial exudative vitreoretinopathy and microcephaly, lymphedema, and chorioretinal dysplasia caused by KIF11 mutations. JAMA Ophthalmol. 2014;132:1393-9. 